\title{
IECA: A FISIOLOGIA POR TRÁS DA FARMACOLOGIA VETERINÁRIA
}

\begin{abstract}
Natália Gageiro Pinto Russo ${ }^{\mathrm{x}}$
RESUMO: O aumento da longevidade dos cães refletiu diretamente na frequência da identificação de afecções cardíacas que apresentam sinais clínicos como dispneia, cianose, tosse seca e síncope. A estratégia fundamental no tratamento de cardiopatias, é o controle pressórico através do bloqueio do sistema renina angiotensina aldosterona (SRAA). $O$ início da aplicação de medicamentos vasodilatadores para uso terapêutico na Medicina Veterinária data dos anos 1970 e 1980. Para tal, os fármacos de classe inibidores de enzima conversora de angiotensina (iECA) atuam no contexto do antagonismo da hipertensão arterial: são bloqueadores dos receptores de angiotensina II. A vasoconstrição, causada por estímulos aos receptores alfa-adrenérgicos, aumento da angiotensina II e maior ação do sistema nervoso simpático, podem causar efeitos deletérios sem o uso dos iECA. Estes medicamentos vasodilatadores atuam na prevenção do comprometimento da função miocárdica, auxiliando no quadro crônico de insuficiência cardíaca (IC) que, em decorrência da redução de débito cardíaco, poderia comprometer a pré e pós-carga pelo aumento da volemia. Em detrimento das consequências da hipotensão, ocorre maior necessidade de uso de oxigênio e energia voltados à contração ventricular, o que potencializa a evolução ao quadro de Insuficiência Cardíaca Congestiva (ICC).
\end{abstract}

Palavras-chave: Insuficiência cardíaca. iECA. Endocardiose de mitral.

ABSTRACT: The increase of dog's life expectancy has been related to identification of cardiac affections that present dyspnoea, cyanosis, dry cough and syncope. A fundamental strategy for treatment of heart disease is the pressoric control by blockade of the renin-angiotensin-aldosterone (RAS) system with inhibitors of angiotensin converting enzyme (ACE). Those agents that are specific antagonists of angiotensin II have allowed veterinary medicine to increase since 1970 and 1980. ACE inhibitors are generally well tolerated, and they improve hemodynamics and clinical sign by controlling vasoconstriction, caused by alpha-adrenergic receptors stimuli. These vasodilator drugs act to prevent the impairment of myocardial

\footnotetext{
${ }^{\mathrm{I}}$ Discente do Curso de Medicina veterinária, Faculdade Metropolitanas Unidas, São Paulo, SP, Brasil. Autora para correspondência: E-mail: nataliagprusso@gmail.com
} 
function, helping in the chronic condition of heart failure (HF) which, as a result of the reduction in cardiac output, could compromise pre- and after-load due to the increase in blood volume. Their usefulness in the treatment of dogs with chronic heart failure, especially in those with chronic valvular disease.

Keywords: Congestive heart failure. ACE inhibitors. mitral valve endocardiosi.

\section{INTRODUÇÃO}

Inibidores da ECA são propostos para tratamento de Insuficiência Cardíaca (IC) por agirem na prevenção do remodelamento ventricular, redução de pré e póscarga, e uma possível regressão da condição de hipertrofia ventricular esquerda. Seu mecanismo de ação envolve o suprimento sistêmico e focal da ativação do Sistema Renina-Angiotensina-Aldosterona (SRAA).

A prescrição deste vasodilatador aumenta a expectativa de vida dos cães acometidos por IC, principalmente em decorrência de cardiomiopatia dilatada e apresentam também melhoras clínicas de suas manifestações sendo algumas delas: cansaço, taquicardia, distrição respiratória e intolerância ao exercício. Inclusive,

numa avaliação clínica, durante a auscultação pode se observar o ritmo de galope, arritmia e sopros.

Em diversos casos, cães podem permanecer assintomáticos por um período prolongado devido a mecanismos compensatórios. Estes aumentam o volume sanguíneo e o tamanho do coração, como por exemplo a dilatação do ventrículo e átrio, hipertrofia miocárdica excêntrica, ou mesmo por meio do mecanismo do sistema nervoso autônomo simpático, associado ao sistema renina-angiotensinaaldosterona. Por meio deles, haverá o remodelamento cardíaco através da ativação do sistema nervoso autônomo simpático, do sistema renina-angiotensina-aldosterona (SRAA), e da liberação do hormônio antidiurético (ADH).

A princípio esta compensação fisiológica irá auxiliar na circulação, já que quando o sangue é regurgitado de volta ao átrio, existe uma queda do fluxo 
sanguíneo geral. Assim, se tem o aumento da volemia por meio da retenção de sódio e água, graças à função da aldosterona, e também se promove uma vasoconstrição, ativada pela angiotensina, auxiliando na perfusão tecidual. Já o SNA Simpático trabalha no aumento da frequência cardíaca e também no aumento do inotropismo positivo, visando recriar a normalização fisiológica da volemia e débito cardíaco que foram diminuídos pela regurgitação sanguínea gerada pelo prolapso valvar.

Este mecanismo salva muitas vidas, mas a cronicidade de sua ativação irá acelerar o processo de decréscimo da função cardíaca, proporcionando alterações sistêmicas, e sendo uma delas a retenção de volume excessiva causada pela ação da aldosterona e $\mathrm{ADH}$, acarretando no acúmulo de sódio, o que influencia diretamente na possibilidade de edema pulmonar e em membros, ascite, efusão e congestão. Já a vasoconstrição crônica em decorrência à ativação da angiotensina aumenta a póscarga, reduz o débito cardíaco e ainda proporciona um maior refluxo valvar.

Já na ativação do sistema nervoso autônomo simpático de forma crônica haverá consequências na função cardíaca diretamente. Por conta da pós-carga, exige maior esforço cardíaco, promovendo um maior requerimento de oxigênio por parte do miocárdio, a ponto de contribuir para a ocorrência do dano celular, e até mesmo fibrose miocárdica, e evoluindo à arritmia cardíaca.

Os barorreceptores são os que proporcionam o feedback necessário para a normalização destes mecanismos, mas por conta da insuficiência cardíaca em decorrência do prolapso valvar, eles terão uma responsividade maior, e vão estimular ainda mais a ativação dos sistemas compensatórios e, por consequência, se tem uma diminuição da resposta inibitória vagal.

Ademais, o mecanismo hormonal compensatório do SRAA tem como objetivo aumentar o volume vascular através de alterações como retenção de água, reabsorção de sódio e cloreto, secreção de potássio e hidrogênio. E a aldosterona também cria um papel comprometedor na influência dos processos de inflamação e fibrose, o que 
contribui, de forma crônica, ao processo de remodelamento patológico e fibrose miocárdica. O hormônio antidiurético terá a

promoção da retenção de líquido e vasoconstrição. A renina, que é produzida nos rins, e atua para facilitar a conversão do angiotensinogênio em angiotensina I, em sua forma inativa, sofre a ação da enzima conversora de angiotensina, para transformá-la em angiotensina II, que é um potente vasoconstritor estimulante da liberação de ADH. Já a Angiotensina II, também produzida no coração, influencia nas estruturas e funcionamento do próprio órgão, ao aumentar a ação de efeitos simpáticos, o que também traz consequências como: alterações no tecido cardíaco, como remodelamento, hipertrofia, inflamação e fibrose.

\section{MECANISMO DE AÇÃO}

A inibição da enzima conversora de angiotensina tem sua ação no bloqueio da enzima que é responsável pela transformação da Angiotensina I em II, o que permite a vasodilatação arteriolar e venosa, além de reduzir a reabsorção de sódio, que

promove aumento de pré-carga, fibrose miocárdica, remodelamento cardíaco e apoptose de miócitos, estabilizando parâmetros hemodinâmicos. Em suma, os efeitos deletérios da ativação crônica do SRAA serão inibidos, refletindo diretamente no pré e pós-carga e na sobrevida do animal.

\section{FÁRMACOS}

O grupo iECA é formado por medicamentos como enalapril, benazepril, ramipril e o lisinopril que são receitados na área da Medicina Veterinária. Destes, os três primeiros necessitam de sua biotransformação por meio de hidrolização das esterases hepáticas para serem pró fármacos, e serão excretadas via renal.

Por tanto, a devida seleção do princípio ativo receitado será baseada em características farmacocinéticas, especialmente vinculadas a sua biodisponibilidade, 
via de eliminação, dose diária e considerando também se precisa de ativação hepática ou não.

\section{CONCLUSÃO}

A prescrição inicial de iECA para animais que tenham manifestações clínicas relacionadas à insuficiência valvar de mitral é um dos principais passos para que ocorra o aumento da expectativa de vida e prevenção de doenças secundárias como a cardiomiopatia dilatada e insuficiência cardíaca congestiva que levaria, por sua vez, ao edema de origem cardiogênico.

\section{REFERÊNCIA BIBLIOGRÁFICA}

ABBOTT, J.A. Degenerative valvular disease. Small Animal Cardiology Secrets, Hanley \& Belfus, Inc. p. 212-215, 2000.

ABREU, C.B, Cardiomiopatia dilatada em cães: revisão de literatura. R. bras. Ci. Vet. v.26, n2, p.28-33, 2019 .

BOON, J.A. Acquired heart disease. Manual of Veterinary Echocardiography, 3aEd., p.26I-382, 2011

COELHO, M.R. et al. Avaliação da deformação miocárdica antes e após uso de pimobendam na cardiomiopatia dilatada. XXIV Congresso de pós-graduação da UFLA, Lavras, 2015.

LOBO, L.L. Cardiomiopatia dilatada canina. Revista Portuguesa de ciências Veterinárias, v.97, n.544, p.153-159, 2002. 


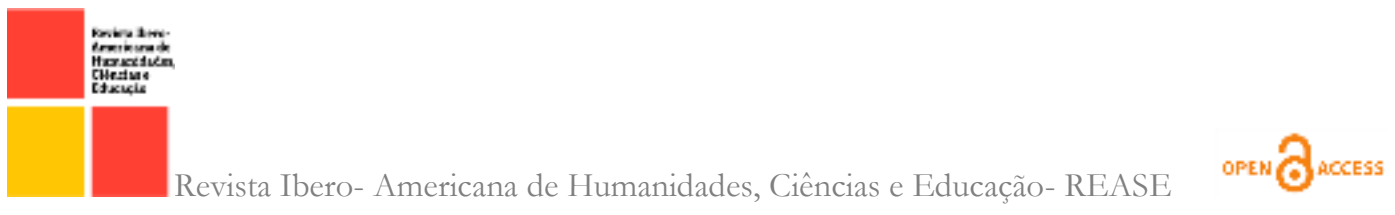

PEREIRA, P.M. Tratamento de insuficiência cardíaca com benazepril em cães com cardiomiopatia dilatada e endocardiose. Arq. Bras. Med. Vet. Zootec. C.57, supl. 2, p.I4I-I48, 2005.

RIBEIRO, J.M. Bloqueio farmacológico do sistema renina-angiotensina-aldosterona: inibição da enzima de conversão e antagonismo do receptor ATı. Rev, Bras. Hipertens 3, 9.293-302, 2000.

SANTOS, A.S. Ativação do sistema renina-angiotensina-aldosterona em cães assintomáticos com doença mixomatosa valvular mitral. 